\title{
Harmonic structure as a determinant of melodic organization
}

\author{
NORMA TAN, RITA AIELLO, and THOMAS G. BEVER \\ Columbia University, New York, New York 10027
}

\begin{abstract}
Musicians and nonmusicians indicated whether a two-note probe following a tonally structured melody occurred in the melody. The critical probes were taken from one of three locations in the melody: the two notes (1) ending the first phrase, (2) straddling the phrase boundary, and (3) beginning the second phrase. As predicted, the probe that straddled the phrase boundary was more difficult to recognize than either of the within-phrase probes. These findings suggest that knowledge of harmonic structure influences perceptual organization of melodies in ways analogous to the influence of clause relations on the perceptual organization of sentences. They also provide evidence that training plays an important role in refining listeners' sensitivity to harmonic variables.
\end{abstract}

Music listening is a complex perceptual task that calls on specific knowledge and perceptual skills. In order to appreciate a musical work, the listener must be able to organize and integrate its parts in structurally consistent ways. To do this, the listener must be sensitive to the structural properties of music through which musical meanings are conveyed. Music theorists have described its internal structure in terms of harmonic systems that formally represent the structural regularities in traditional Western compositional practice. Harmonic structure specifies the systematic relationships underlying tonal organization. Harmony provides the structural framework of a musical "language" and, thus, functions as a part of a musical "grammar."

The present research explores the possibility that listeners use intuitive knowledge of the system of harmonic rules to organize their perception of melodies. Studies of simple pattern perception and learning (Garner, 1974; Kotovsky \& Simon, 1973; Leeuwenberg, 1972; Restle, 1970; Vitz \& Todd, 1969) observe that general rules and procedures govern the analysis of serial patterns regardless of modality. Using different kinds of stimuli (random tones, flashing lights, numbers, etc.), these studies demonstrate that listeners are able to abstract pattern regularities from temporally structured events. Experiments of this kind, however, do not explore how humans process natural sequential struc-

We thank Michael Tanenhaus and Lucia Kellar for their valuable support and advice during the execution of this research. We are also grateful to John Ritter for his comments on an earlier draft of the manuscript. This research was supported in part by a Sigma Xi Grant-in-Aid of Research to the first author and a Spencer Foundation Grant to the third author. Reprint requests should be sent to N. Tan, Room 734, Office of Educational Evaluation, NYC Board of Education, 110 Livingston Street, Brooklyn, New York 11201. R. Aiello is also with the Department of Psychology, New York University, New York, New York 10003. ture. The study of melody perception provides us with a useful tool for exploring serial behavior in a modality that, like language, is indigenous to humans and possesses intrinsic formal structure. Moreover, through music, we may be able to understand the perceptual implications of natural structure in a context in which no reference is made to extrinsic, real-world objects and events. Additionally, because musical skills are developed to different degrees in adults, music provides a better opportunity than language to observe the effects of individual differences and special experience on the perception of a complex natural structure.

Perceiving music may involve processes similar to those that operate in language. Research on sentence perception has revealed the importance of segmentation: As listeners process incoming sequences of words, the words become grouped together and reorganized into phrases and elementary propositional units of meaning (see Fodor, Bever, \& Garrett, 1974, for a review). This has been experimentally demonstrated in several ways. A brief click is reported as occurring between clauses, even when it occurs during a clause. The following sentences provide an example: (1) Harry sipped the old milk . . . and got sick. (2) Because Harry sipped the old milk ... he got sick. (3) Although Harry sipped the old milk ... he got sick. (4) After Harry's sipping the old milk ... he got sick. (5) After Harry's sips of the old milk ... he got sick. The click would be most frequently reported as occurring between "milk" and "and" in Sentence 1, even if it were objectively located in the word "milk," because the first clause coheres together, displacing interruptions to its boundary (Bever, Lackner, \& Kirk, 1969; Carroll \& Bever, 1976). Analogously, listeners can decide that a word occurred in a just-heard sentence more quickly if the word is in the second clause han if it is in the first, for example, "milk" vs. "he" (Caplan, 1972; Townsend, Ottaviano, \& Bever, 1979). Finally, subjects take longer to decide that a word 
phrase occurred in a sentence they just heard if it is a between-clause subsequence, such as "milk he" vs. "he got" (Suci, Ammon, \& Gamlin, 1967). There is also evidence of the immediate behavioral coherence of clauses during ongoing processing. Tanenhaus and Carroll (1975) have elaborated a "functional clause hierarchy" that reflects the extent to which a clause is propositionally complete and therefore perceptually independent of other clauses: The more independent a clause is from what follows, the stronger are the effects of the segmentation. For example, Carroll and Tanenhaus (1978) found that the final boundary of an initial subordinate clause (as in Sentence 2) attracts clicks less strongly than the boundary of a main clause. Townsend and Bever (1978) confirmed the clause difference by showing that the latency difference to identify a word before and after a subordinate clause boundary is smaller than the difference caused by an intervening main clause boundary. They also showed that this main/ subordinate clause difference is most extreme for conjunctions like "although" (e.g., Sentence 3 ) that explicitly inform the listener that he/she will require some information from the main clause to aid in interpreting the subordinate clause. In brief, (1) listeners segregate meaning units of speech together, and (2) insofar as a unit is incomplete and depends on what follows, listeners refrain from segmenting it.

Simple melodies can show the same kind of segmentation effects as do sentences. For example, Gregory (1978) observed boundary effects to occur when listeners were instructed to organize the same six-note melody in two ways, either as two groups of three notes or as three groups of two notes. Judgment of the position of a click (presented at the opposite ear from the melody) tended toward the perceived boundaries. In Gregory's study, instructional set was shown to be sufficient in producing organizational effects of the kind observed. Dowling (1973) investigated the effect of rhythmic grouping on chunking and memory for brief melodies. Subjects were asked to identify a five-tone test sequence from a "list" of four five-tone melodies on the basis of rhythm and melodic contour. Recognition for test-tone sequences corresponding to a melody from the list was better than recognition for test-tone sequences that bridged across two melodies from the list of tone sequences.

Organization according to musically defined structural units may also cause grouping in melody perception. In music, organizational units are suggested by formal structural variables. Harmony is one such variable. Previous research has not dealt with harmonic aspects of musical structure. Most investigators have tended to focus on memory for specific forms of acoustical information, such as pitch (see Deutsch, 1977, for a review), configurational structure (Cuddy, Cohen, 1976; Dowling, 1972, 1978; Dowling \& Fujitani, 1971; Koffka, 1935/1963; White, 1960), or rhythmic pattern
(Martin, 1972; Restle, 1970, 1972; Restle \& Brown, 1970a, 1970b; Sturges \& Martin, 1974). However, there is some evidence that harmonic structure does indeed play a role in the retention of musical information. Dewar, Cuddy, and Mewhort (1977) found that recognition of simple pitches presented within the context of musical (tonally structured) sequences was better than recognition of single pitches presented within the context of random (computer-generated) sequences. The investigators suggested that listeners were able to recognize distractor tones that did not occur in the musical sequences by using knowledge of the key or tonality. Dowling (1978) has proposed that the musical scale acts as a conceptual schema that combines with contour information to facilitate memory for melodies. Krumhansl (1979), using multidimensional scaling techniques, has provided evidence indicating that memory representation for pitch includes information about complex patterns of tonal relationships. Similarity judgments between pairs of tones presented after providing a tonal context revealed consistent tendencies for tones outside the key of the context to be related to tones within the key. They also reflected differences in the degree of stability of tones within the key. Tones of the major triad were the most stable components of the representation. Shepard (Note 1) has reported other experiments in collaboration with Krumhansl illustrating marked individual differences in representational space linked with musicianship. Other investigators have observed categorical perception of pitch corresponding to the intervals of the musical scale, particularly among musicians (Burns \& Ward, 1974, 1975; Locke \& Kellar, 1973; Siegel \& Siegel, 1977).

The present study examines whether harmonic structure influences the perception of melodies. In particular, it focuses on whether listeners use harmonic cues to segment melodies into musical phrase units. The phrase is a basic structural unit in music insofar as it presents a syntactically complete musical idea that acts in balanced relationship with other component material within a composition. Characteristically, phrases end with a pattern of notes called a cadence, which suggests movement toward a point of harmonic closure. The effect of closure achieved by the cadence can be explained by the fact that traditional Western music is built on a transitively ordered system of tonal relationships in which tones differ in their functions relative to each other. All tones have a tendency to support or progress toward tones of greater stability in the ordering. The cadence constitutes an important stylistic means by which movement toward more stable points is achieved. There are several types of cadence; they differ with respect to their point of harmonic arrival. For example, a full cadence arrives at the tonic chord (the I chord of the key and the central point in the scheme of tonal relationships) and implies strong closure. A semicadence involves movement towards the 
dominant (the $\mathrm{V}$ chord of the key) and implies partial but not complete closure, since the dominant is secondary to the tonic in the tonal order. The type of cadence concluding a phrase largely determines the degree of finality associated with the phrase. Structural units normally incorporate dynamic movement through characteristic patterns of harmonic change. The quality of a phrase as determined by the cadence has an important bearing on the overall effect of the larger structure. For this reason, we often find normative structures that achieve resolution through harmonic means whereby the cadence is critical. Thus, for example, the musical period, a two-phrase unit, often consists of a first phrase ending in a semicadence and a second phrase ending in a full cadence. There is a formal similarity between the distinction of full vs. semicadence in melodies and main vs. subordinate clauses in sentences. In each case, one structure is complete and independent of the other (full cadence/main clause), whereas the other structure (semicadence/subordinate clause) is realtively incomplete and dependent on the former structure (full/main) for resolution. We noted that this distinction is reflected in differing degrees of closure in language. The present study explores whether there are analogous differences in the degree of closure in music. Put succinctly, does processing involve segregation of harmonically defined melodic phrases? Is this segmentation more extreme for phrases ending in full cadence than for those ending in semicadence?

As a means of determining whether the musical phrase serves as a processing unit, the present study employed a probe-recognition technique used in studies of sentence perception. Evidence that grammatical phrases serve as processing units in sentence perception is partially based on the finding mentioned above: A two-word probe that straddles a phrase boundary in a sentence is more difficult to recognize than a probe drawn from within a phrase (Suci et al., 1967). In the present task, musicians and nonmusicians heard a series of items, each item consisting of a two-phrase melody followed by a two-note probe. After each item, subjects were to indicate whether the probe occurred in the melody.

The probes of interest were taken from three locations in the melody: the two notes (1) preceding the phrase boundary (the last two notes of the first phrase), (2) straddling the phrase boundary (the last note of the first phrase and the first note of the last phrase), and (3) following the phrase boundary (the first two notes of the last phrase). Probes straddling the harmonic phrase boundary were expected to be more difficult to recognize than the within-phrase probes, particularly for musicians. The type of cadence occurring at the end of the first phrase was varied in order to determine whether immediate organization would be affected by differences in implied closure. It was expected that predicted differences in probe performance would be most pronounced when the first phrase of the melody ended with a full cadence as opposed to a semicadence, since, musically speaking, a full cadence indicates stronger closure than a semicadence does.

\section{METHOD}

\section{Subjects}

Thirty musicians drawn from a professional music school or reporting current professional involvement and 30 nonmusicians reporting less than 3 years of formal musical training participated in the experiment.

\section{Stimulus Materials}

A series of 42 items, 2 practice and 40 experimental, was used in the experiment. Each item consisted of a two-phrase melody followed by a 2 -sec interval and then a two-note probe. Items were separated by a $10 \mathrm{sec}$ interval. Of the experimental items, 24 consisted of a melody paired with a true probe and 10 consisted of a melody paired with a false probe; 6 items were fillers. There were three types of true probes: the two notes (1) ending the first phrase, (2) straddling the phrase boundary, and (3) beginning the second phrase (see Figure 1). The false probe presented a unique two-note sequence that did not occur in the melody but was in the same key. Each filler melody was paired with a probe that occurred more than once in the melody.

The melodies were composed for the purpose of the experiment, according to standardized rules of 19 th century Western tonal harmony. The sequence of tones in the melodies outlined chordal relationships, so that harmonic structure was implicit in the melodic line. Each melody could be described as consisting of a series of broken chords, with passing tones occasionally introduced to produce a smoother melodic line. The melodies always began and ended with a tonic chord sequence and did not modulate; that is, they did not move outside the established key. The intended effect of these manipulations was to maintain a sense of one tonality throughout a melody. The pitch range of each melody was approximately one octave. Over all melodies, the pitch range was from $G 3(196 \mathrm{~Hz})$ to $\mathrm{G} \# 5(830.61 \mathrm{~Hz})$. There was no thy thmic variation in the melodies: All notes were of equal duration $(.599 \mathrm{sec})$ and were presented at a constant rate $(100$ beats $/ \mathrm{min})$ for all sequences. The melodies were presented in different keys, randomly chosen and assigned.

Each melody consisted of two phrases of approximately equal length. Phrase lengths ranged from 7 to 16 notes; melody lengths ranged from 16 to 27 notes. In 11 of the items, the first phrase ended with a full cadence by returning (from dominant) to a chord sequence ending on the tonic. In the remaining 13 items, the first phrase ended with a semicadence by arriving at the dominant. Each phrase involved a harmonic progression of three or four broken chord sequences.

The stimuli were performed and recorded on a Moog synthesizer. They were presented on a stereo tape recorder through loudspeakers at a comfortable listening level.

\section{Procedure}

The pairing of melody and probe types was counterbalanced across three presentation versions in a modified Latin square design, so that each of 24 melodies was paired once with each of the three true probe types over all presentation versions. Ten additional melodies were paired with false probes. One-third

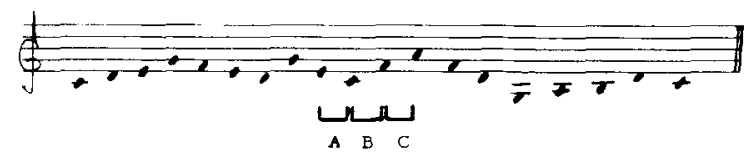

Figure 1. Example melody with probe locations indicated ( $A$ = first-phrase probe; $B=$ between-phrase probe; $C=$ lastphrase probe). 
of the subjects from each group, musicians and nonmusicians, served in each presentation condition. All subjects heard the same order of melodies. Levels of cadence and probe were crossed by randomly arranging items within five blocks, each block containing two examples of each possible cadence-probe pairing. The data set treated in the analysis consisted of scores obtained on 11 full-cadence melodies and 13 semicadence melodies; each melody was paired an equal number of times with each of the four probe types.

Subjects were tested in groups. The subject's task was to indicate whether the two-note sequence (probe) presented directly after each melody had occurred in the melody by placing a check in the appropriate space on an answer sheet. Subjects were initially presented two example items, after which the experimenter stopped the tape to answer questions about the task. During the presentation of the experimental items, no feedback was given.

\section{RESULTS}

Scores for each subject were obtained by computing the percentage of correctly recognized items for each probe type. The mean percentage scores of musicians and nonmusicians are presented in Table 1.

Responses were analyzed using a 2 by 4 by 2 ANOVA with musical experience as a between-subjects variable and probe and cadence type as within-subjects variables. A significant effect was found for probe type $[\mathrm{F}(3,174)$ $=9.55, p<.001]$. As can be seen from Table 1, performance on the within-phrase probes. Significant interactions of probe type and musical experience $[F(3,174)$ $=4.51, \mathrm{p}<.005]$, cadence and probe type $[F(3,174)=$ $5.41, \mathrm{p}<.001]$, and cadence type, probe type, and musical experience $[\mathrm{F}(3,174)=3.25, \mathrm{p}<.05]$ were also obtained. Separate two-way ANOVAs were performed on the data of the musicians and the nonmusicians; these analyses considered responses on the three true probe types and the two cadence types. Musicians showed a significant effect for probe type $[F(2,58)=13.72$, $\mathrm{p}<.001]$ and for the interaction of cadence and probe type $[F(2,58)=5.43, p<.01]$. One-tailed paired $t$ tests were used to compare musicians' recognition accuracy on the true probe types. These tests indicated significantly poorer performance on the betweenphrase probe compared with performance on each of the within-phrase probes (all alphas $<.05$ ) in both cadence conditions. The ANOVA on the data of the nonmusicians yielded no significant effects.

Another ANOVA that treated each melody as a case was performed in order to determine whether these effects generalize to a new population of melodies (see Clark, 1973). Scores for each melody in which a true probe occurred were obtained by summing scores for each of the three true probe locations across all subjects. This analysis also yielded a significant effect for probe type $[F(2,40)=5.29, p<.01]$. These results are consistent with those of the by-subject analysis.

In addition to the above findings, other differences were observed bearing on the effect of cadence. A comparison of first- and last-phrase probe performance revealed a unique pattern for musicians in the fullcadence condition. On full cadence, musicians' performance on last-phrase probes was markedly superior to their performance on first-phrase probes $(t=2.52$, $\mathrm{p}<.05$, two-tailed test). This difference did not obtain in any of the other group by cadence conditions. In addition, musicians' performance on last-phrase probes was significantly better in the full-cadence condition than in the semicadence condition $(t=3.14, p<.01$, two-tailed test); also, their performance on last-phrase probes in the full-cadence condition was significantly better than nonmusicians' performance in the same condition $(t=2.01, p<.05$, two-tailed test $)$. These results relating to the probe performance of musicians in the full cadence all suggest that musicians are responding to full and semicadences in qualitatively distinct ways, unlike nonmusicians.

A more direct comparison of musicians' and nonmusicians' performance on first- and last-phrase probes over the two cadence types was made by calculating per subject, for full and semicadence separately, the difference between scores obtained on first-phrase probes and last-phrase probes; a score representing the difference between these two values was then assigned. A nonparametric test of the equality of two medians performed on these scores indicated a significant difference between the two groups on this measure $\left(\chi^{2}=9.60\right.$, $p<.01)$. This suggests that, for musicians, the difference in performance between last- and first-phrase probes was affected more strongly by the type of cadence than it was for nonmusicians.

These findings all suggest that full cadences are associated with relatively stronger closure in musicians, leading to better performance on last-phrase probes and worse performance on first-phrase and between-phrase probes. The fact that musicians performed more poorly than nonmusicians on the between-phrase probe in the

Table 1

Mean Percentage of Correct Responses by Musicians and Nonmusicians on Each Probe Type for Full- and Semicadence Melodies

\begin{tabular}{|c|c|c|c|c|c|c|c|c|c|c|c|}
\hline \multirow[b]{3}{*}{ Group } & \multirow[b]{3}{*}{ Cadence Type } & \multicolumn{10}{|c|}{ Probe Type } \\
\hline & & \multicolumn{2}{|c|}{ First Phrase } & \multicolumn{2}{|c|}{ Between Phrases } & \multicolumn{2}{|c|}{ Last Phrase } & \multicolumn{2}{|c|}{ Average Hit Rate } & \multicolumn{2}{|c|}{ False } \\
\hline & & Mean & SE & Mean & SE & Mean & SE & Mean & SE & Mean & $\mathrm{SE}$ \\
\hline Musicians & $\begin{array}{l}\text { Full Cadence } \\
\text { Semicadence }\end{array}$ & $\begin{array}{l}.52 \\
.61\end{array}$ & $\begin{array}{l}.27 \\
.29\end{array}$ & $\begin{array}{l}.34 \\
.42\end{array}$ & $\begin{array}{l}.24 \\
.25\end{array}$ & $\begin{array}{l}.72 \\
.58\end{array}$ & $\begin{array}{l}.22 \\
.19\end{array}$ & $\begin{array}{l}.53 \\
.54\end{array}$ & $\begin{array}{l}.27 \\
.25\end{array}$ & $\begin{array}{l}.46 \\
.27\end{array}$ & $\begin{array}{l}.23 \\
.20\end{array}$ \\
\hline Nonmusicians & $\begin{array}{l}\text { Full Cadence } \\
\text { Semicadence }\end{array}$ & $\begin{array}{l}.65 \\
.57\end{array}$ & $\begin{array}{l}.25 \\
.26\end{array}$ & $\begin{array}{l}.54 \\
.45\end{array}$ & $\begin{array}{l}.29 \\
.27\end{array}$ & $\begin{array}{l}.58 \\
.58\end{array}$ & $\begin{array}{l}.29 \\
.20\end{array}$ & $\begin{array}{l}.59 \\
.53\end{array}$ & $\begin{array}{l}.28 \\
.25\end{array}$ & $\begin{array}{l}.55 \\
.43\end{array}$ & $\begin{array}{l}.25 \\
.22\end{array}$ \\
\hline
\end{tabular}


full-cadence condition $(\mathrm{t}=2.99, \mathrm{p}<.01$, two-tailed test) and on the first-phrase probe in the full-cadence condition (nonsignificant trend, $t=1.95, p=.057$, two-tailed test) is a striking demonstration of the effect of closure. Furthermore, false positive rates were relatively higher for full cadence for musicians. This would be predicted if full cadences occasion more forgetting of the first musical phrase and, therefore, more false positive guessing.

The false positive rates were high (see Table 1). However, they were consistently lower than all their corresponding true positive rates, except for between-phrase probes in full cadences. Accordingly, the differences brought about by the ANOVAs are differences among response categories at or above guessing rates. Table 2 summarizes the results in terms of $\mathrm{d}^{\prime}$ scores. The values shown support the findings from the original analysis, providing some assurance that the observed effects were not the result of response bias. ${ }^{1}$

Serial position effects have been shown to exist in memory for tonal sequences (Leshowitz \& Hanzi, 1974). A possible objection to the present explanation for the results might be that differences in performance on the three critical probe types were in fact due to the serial position of the probes. To test this, performance on these probe types was compared as a function of serial position (Figures $2 \mathrm{a}-2 \mathrm{~d}$ ). This comparison indicated that the observed probe effects could not be accounted for by a serial position explanation. Between-phrase probes tended to be responded to less well than within-phrase probes, particularly at later serial positions. For musicians in full cadence, the probes showed a clear difference in performance that held constant across serial positions, further implying that musicians organize and store the phrases as distinct units.

To determine the influence of the size of the pitch interval of the probe on subjects' performance, ${ }^{2}$ probe interval size (measured as the distance in semitones between the two tones in the probe) for each of the four probe types was correlated with the performance of the musicians and nonmusicians separately. According to this analysis, musicians showed a positive and significant correlation between first-phrase probe size and performance $(\mathrm{r}=.57, \mathrm{p}<.05)$, as well as last-phrase probe size and performance $(r=.53, p<.05)$ in the fullcadence condition only. No other correlations were

Table 2

d'Analysis

\begin{tabular}{cccc}
\hline Cadence & \multicolumn{3}{c}{ Probe Type } \\
\cline { 2 - 4 } Type & $\begin{array}{c}\text { First } \\
\text { Phrase }\end{array}$ & $\begin{array}{c}\text { Between } \\
\text { Phrases }\end{array}$ & $\begin{array}{c}\text { Last } \\
\text { Phrase }\end{array}$ \\
\hline & \multicolumn{3}{c}{ Musicians } \\
Full Cadence & .15 & -.28 & .68 \\
Semicadence & .89 & .41 & .81 \\
& & Nonmusicians & \\
Full Cadence & .26 & -.03 & .07 \\
Semicadence & .36 & .05 & .38 \\
\hline
\end{tabular}
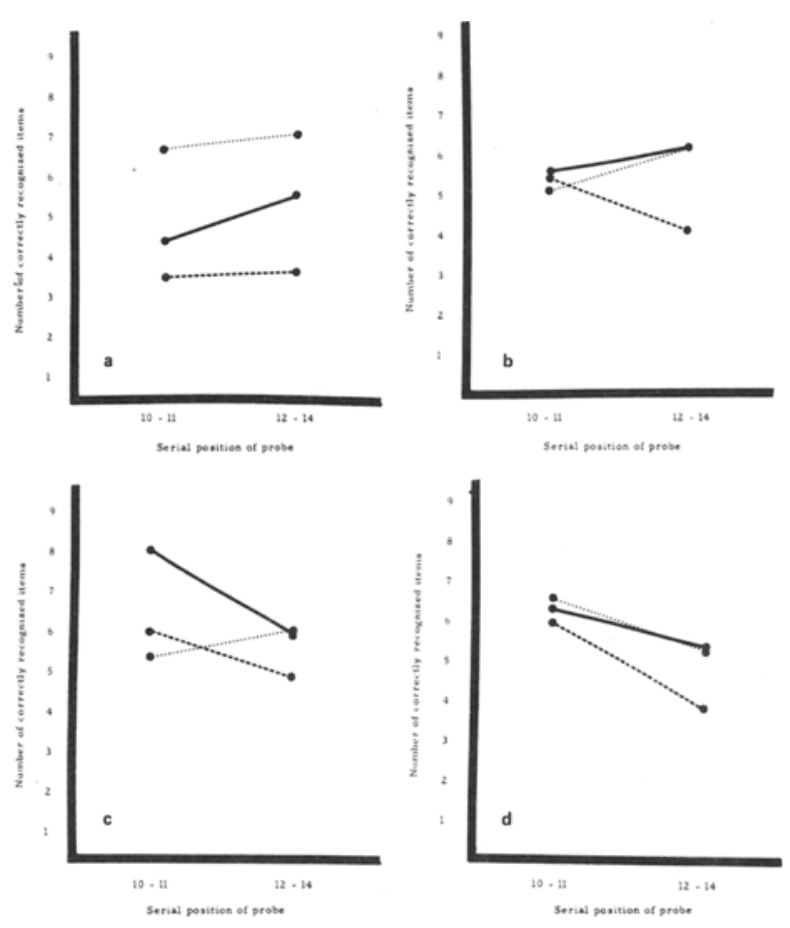

Figure 2. Number of items correctly recognized by musicians on (a) full-cadence and (b) semicadence melodies and by nonmusicians on (c) full-cadence and (d) semicadence melodies as a function of serial position of probe. Solid lines = first phrase; dashed lines $=$ between phrase ; dotted lines $=$ last phrase.

significant for either group of subjects. This pattern of findings lends support to the notion of harmonic segmentation and of the greater sensitivity of musicians to the harmonic implications of the stimuli.

\section{DISCUSSION}

The finding that musicians (and to a lesser extent nonmusicians) perform poorest on between-phrase probes suggests that harmonic structure does have an influence on the behavioral organization of melodies. Moreover, it suggests that musicians and nonmusicians differ in their sensitivity to harmonic structure. Evidence of a probe effect among musicians indicates that they are responsive to harmonic cues to phrase structure in a melody; in addition, differences in degree of closure as implied by the type of cadence are reflected in a difference in the strength of the probe effect. Musicians showed stronger probe effects in the full-cadence condition than in the semicadence condition. Thus, musicians not only segment melodies into harmonic phrase units but also show this effect more strongly when the type of cadence implied at the phrase boundary indicates fuller closure. Musical experience, by refining the listener's response to the harmonic dimensions of a melody, critically determines the extent to which harmonic variables influence processing. The suggestion that musicians and nonmusicians process melodies in 
a distinctly different manner is also supported by other differences in performance observed between the two groups. Musicians' performance in the full-cadence condition showed not only the strongest probe effect, but also poorer accuracy on first-phrase probes than on last-phrase probes. By contrast, performance on lastphrase probes in the full-cadence condition was significantly better for musicians than for nonmusicians. A possible explanation for this pattern of results is that in the full-cadence condition, musicians recode the first phrase into a form that discards information about the exact sequence of notes in the melody. Poorer performance on first-phrase probes would result, since information about the exact sequence of notes in the first phrase is no longer available. These effects should be most apparent in the full-cadence condition, in which the first and last phrase represent two relatively independent ideas. It is reasonable that performance on lastphrase probes will be superior for musicians; memory for notes of the last phrase should be better if we assume that the first phrase has been fully processed.

Analogous findings have been reported with regard to the perception of main and subordinate clauses in sentences. Listeners appear to have better access to the verbatim form of subordinate clauses immediately or shortly after hearing a sentence; however, access is better to the semantic meaning of main clauses (see Townsend \& Bever, 1978; also Flores d'Arcais, 1978; Harris, 1976; Singer, 1976; Singer \& Rosenberg, 1973; Smith \& McMahon, 1970). Presumably, main clauses are encoded at a deeper level in memory.

Overall, the results of the present study strongly suggest that harmonic structure plays an important role in the perceptual organization of melodies. The finding that listeners show perceptual segmentation of melodies on the basis of harmonic phrase units indicates that they are using knowledge of harmonic structure to organize the musical percept. In addition, the present findings point to the influence of musical experience in developing listeners' sensitivity to harmonic variables. The simultaneous effect of phrase and cadence on perceptual segmentation observed in the performance of the musicians suggests that the ability to respond to harmonic dimensions in music becomes more refined with training.

We started this report with a review of the difference in closure occasioned by main and subordinate clauses. We have found a similar distinction in the processing of melodies with full and semicadences. This is important, since it suggests that there are general processes that operate independently of modality with natural structures. In so doing, we have tried to demonstrate that the experimental study of music can serve as a tool for understanding the nature of integrated serial processing in humans. At the same time, in providing this initial evidence for the importance of harmonic structure in determining perceptual organization of melodies, the present study offers new and interesting possibilities for the study of musical processes. An experimental approach that focuses on the interaction of representational knowledge and stimulus structure is crucial if we are to understand musical experience in the context of meaningful listening.

\section{REFERENCE NOTE}

1. Shepard, R. N. Individual differences in the perception of musical pitch. Paper presented at the National Symposium on the Applications of Psychology to the Teaching and Learning of Music: The Ann Arbor Symposium, Session II, July 30 to August 2, 1979.

\section{REFERENCES}

Bever, T. G., Lackner, J. R., \& Kirk, R. The underlying structure of sentences are the primary units of immediate speech processing. Perception \& Psychophysics, 1969, 5, 225-231.

BURNs, E. M., \& WARD, W. D. Categorical perception of musical intervals. Journal of the Acoustical Society of America, 1974, $55,456$.

Burns, E. M., \& WARD, W. D. Further studies in musical interval perception. Journal of the Acoustical Society of America, 1975,58, S132.

Caplan, D. Clause boundaries and recognition latencies for words in sentences. Perception \& Psychophysics, 1972, 12, 73-76.

Carroll, J. M., \& Bever, T. G. Sentence comprehension: A study in the relation of knowledge to perception. In E. C. Carterette \& M. P. Friedman (Eds.), The handbook of perception (Vol. 5): Language and speech. New York: Academic Press, 1976.

Carroll, J. M., \& Tanenhaus, M. K. Functional clauses and sentence segmentation. Journal of Speech and Hearing Research, 1978, 21, 693-708.

CLARK, H. H. The language-as-fixed-effect fallacy. Journal of Verbal Learning and Verbal Behavior, 1973, 12, 335-360.

Cuddy, L. L., \& Cohen, A. J. Recognition of transposed melodic sequences. Quarterly Journal of Experimental Psychology, 1976, 28, 255-270.

DeUtsch, D. Memory and attention in music. In M. Critchley \& R. A. Henson (Eds.), Music and the brain. Springfield, Ill: Thomas, 1977.

Dewar, K. M., Cuddy, L. L., \& Mewhort, D. J. K. Recognition memory for single tones with and without context. Journal of Experimental Psychology: Human Learning and Memory, 1977, 3, 60-67.

Dowling, W. J. Recognition of melodic transformations: Inversion, retrograde, and retrograde inversion. Perception \& Psychophysics, 1972, 12, 417-421.

Dowling, W. J. Rhythmic groups and subjective chunks in memory for melodies. Perception \& Psychophysics, 1973, 14, 37-40.

Dowling, W. J. Scales and contour: Two components of a theory of memory for melodies. Psychological Review, 1978, 85, 341-354.

Dowlina, W. J., \& Fujitani, D. S. Contour, interval, and pitch recognition in memory for melodies. Journal of the Acoustical Society of America, 1971, 49, 524-531.

Flores D'Arcais, G. B. The perception of complex sentences. In W. J. Levelt \& G. B. Flores d'Arcais (Eds.), Studies in the perception of language. Wiley, London, 1978. 
Fodor, J. A., Bever, T. G., \& GArretT, M. F. The psychology of language. New York: Mc-Graw-Hill, 1974.

Garner, W. R. The processing of information and structure. Potomac, Md: Erlbaum, 1974.

Gregory, A. H. Perception of clicks in music. Perception \& Psychophysics, 1978, 24, 121-174.

HarRis, R. J. Memory for negation in coordination and complex sentences. Journal of Experimental Psychology: Human Learning and Memory, 1976, 2, 308-314.

KoFrka, K. Priniciples of Gestalt psychology. New York: Harcourt, Brace, \& World, 1963. (Orginally published, 1935.)

Kotovsxy, K., \& Simon, H. A. Empirical tests of a theory of human acquisition of concepts for sequential patterns. Cognitive Psychology, 1973, 4, 399-424.

KrumhansL, C. L. The psychological representation of musical pitch in a tonal context. Cognitive Psychology, 1979, 11, 346-374.

LEEUWENBERG, E. L. L. Quantitative specification of information in sequential patterns. Psychological Review, 1972, 79, 487-509.

Leshowitz, B., \& Hanzi, R. Serial position effects for tonal stimuli. Memory \& Cognition, 1974, 2, 112-116.

LOCKE, S., \& KELLAR, L. Categorical perception in a nonlinguistic mode. Cortex, 1973, 9, 355-368.

Martin, J. Rhythmic (hierarchical) vs. serial structure in speech and other behavior. Psychological Review, 1972, 79, 487-509.

Restle, F. Theory of serial pattern learning: Structural trees. Psychological Review, 1970, 77, 481-495.

Restle, F. Serial patterns: The role of phrasing. Journal of Experimental Psychology, 1972, 92, 385-390.

Restle, F., \& Brown, E. R. Organization of serial pattern learning. In G. H. Bower (Ed.), The psychology of learning and motivation (Vol. 4). New York: Academic Press, 1970. (a)

Restle, F., \& BRown, E. R. Serial pattern learning. Journal of Experimental Psychology, 1970, 83, 120-125. (b)

Siegel, J. A., \& Siegel, W. Categorical perception of tonal intervals: Musicians can't tell sharp from flat. Perception \& Psychophysics, 1977, 21, 399-407.

Singer, M. Thematic structure and the integration of linguistic information. Journal of Verbal Learning and Verbal Behavior, $1976,15,549-558$.

Singer, M., \& Rosenberg, S. The role of grammatical relations in the abstraction of linguistic ideas. Journal of Verbal Learning and Verbal Behavior, 1973, 12, 273-284.

SMITH, K., \& McMAhON, L. Understanding order information in sentences: Some recent work at Bell Laboratories. In G. B. Flores d'Arcais, \& W. J. Levelt (Eds.), Advances in psycholinguistics. Amsterdam: North-Holland Publishing Co., 1970.

Sturges, P. T., \& Martin, J. G. Rhythmic structure in auditory temporal pattern perception and immediate memory. Journal of Experimental Psychology, 1974, 102, 377-383.

Suci, G., Ammon, P., \& Gamlin, P. The validity of the probelatency technique for assessing structure in language. Language and Speech, 1967, 10, 69-88.

Tanenhaus, M. K., \& Carnoll, J. M. The clausal processing hierarchy ... and nouniness. In R. Grossman, J. San, \& T. Vance (Eds.), Papers from the parasession on functionalism. Chicago: Linguistic Society, 1975.

TOWNSEnd, D. J., \& Bever, T. G. Interclause relations and clausal processing. Journal of Verbal Learning and Verbal Behavior, 1978, 17, 509-521.

Townsend, D. J., Ottaviano, D., \& Bever, T. G. Immediate memory for words from main and subordinate clauses at different age levels. Journal of Psycholinguistic Research, 1979, 8, 83-101.

ViTz, P. C., \& Tond, T. C. A coded-element model of the perceptual processing of sequential stimuli. Psychological Review, 1969, 76, 433-449.

White, B. W. Recognition of distorted melodies. American Journal of Psychology, 1960, 73, 100-107.

\section{NOTES}

1. Conventional signal detection analyses usually apply only to situations in which categories of false items correspond to categories of true items. In this study, false items do not differcntially correspond to the three categories of true items as defined by probe location. Table 2 was included at the request of the editor.

2. The mean interval size for the four probe types, measured in semitones, by cadence type was as follows:

\begin{tabular}{llcccr} 
& & \multicolumn{4}{c}{ Probe Type } \\
\cline { 3 - 6 } & & $\begin{array}{c}\text { First } \\
\text { Phrase }\end{array}$ & $\begin{array}{c}\text { Between } \\
\text { Phrases }\end{array}$ & $\begin{array}{c}\text { Last } \\
\text { Phrase }\end{array}$ & False \\
\hline \multirow{2}{*}{ Full Cadence } & Mean & 2.91 & 4.36 & 3.00 & 4.20 \\
& SD & 1.04 & 2.46 & 1.67 & .84 \\
Semicadence & Mean & 3.46 & 4.31 & 2.92 & 4.60 \\
& SD & 1.51 & 2.63 & 1.89 & 2.07
\end{tabular}

Due to the fact that the mean interval size of the probes differed, a post hoc comparison of performance on small and large intervals was carried out. This analysis showed that for both musicians and nonmusicians on both full and semicadence melodies, performance on between-phrase probes remained consistently lower than on within-phrase probes. The means and standard deviations are reported below $(B P=$ between-phrase probes).

\begin{tabular}{|c|c|c|c|c|c|c|c|}
\hline & & \multicolumn{6}{|c|}{ Probe Type } \\
\hline & & \multicolumn{3}{|c|}{ Musicians } & \multicolumn{3}{|c|}{ Nonmusicians } \\
\hline & & First & BP & Last & First & $\mathrm{BP}$ & Last \\
\hline & & \multicolumn{6}{|c|}{ Full Cadence } \\
\hline Small Interval & $\begin{array}{l}\text { Mean } \\
\text { SD }\end{array}$ & $\begin{array}{r}4.17 \\
.75\end{array}$ & $\begin{array}{l}6.38 \\
2.07\end{array}$ & $\begin{array}{l}4.25 \\
2.06\end{array}$ & $\begin{array}{l}6.83 \\
1.60\end{array}$ & $\begin{array}{l}5.88 \\
2.53\end{array}$ & $\begin{array}{l}5.25 \\
1.71\end{array}$ \\
\hline \multirow[t]{2}{*}{ Large Interval } & $\begin{array}{l}\text { Mean } \\
\text { SD }\end{array}$ & $\begin{array}{l}6.00 \\
2.00\end{array}$ & $\begin{array}{l}8.33 \\
1.15\end{array}$ & $\begin{array}{l}3.14 \\
1.21\end{array}$ & $\begin{array}{l}6.60 \\
3.78\end{array}$ & $\begin{array}{r}5.67 \\
.58\end{array}$ & $\begin{array}{l}5.43 \\
1.81\end{array}$ \\
\hline & & \multicolumn{6}{|c|}{ Semicadence } \\
\hline Small Interval & $\begin{array}{l}\text { Mean } \\
\text { SD }\end{array}$ & $\begin{array}{l}5.00 \\
2.45\end{array}$ & $\begin{array}{l}5.67 \\
2.69\end{array}$ & $\begin{array}{l}4.43 \\
3.15\end{array}$ & $\begin{array}{l}6.83 \\
4.12\end{array}$ & $\begin{array}{l}5.44 \\
1.33\end{array}$ & $\begin{array}{l}4.57 \\
2.51\end{array}$ \\
\hline Large Interval & $\begin{array}{l}\text { Mean } \\
\text { SD }\end{array}$ & $\begin{array}{l}7.00 \\
1.15\end{array}$ & $\begin{array}{l}6.50 \\
3.32\end{array}$ & $\begin{array}{l}4.17 \\
3.31\end{array}$ & $\begin{array}{l}6.14 \\
1.68\end{array}$ & $\begin{array}{l}6.25 \\
3.86\end{array}$ & $\begin{array}{l}4.17 \\
1.47\end{array}$ \\
\hline
\end{tabular}

(Received for publication November 15, 1979; revision accepted April 23, 1981.) 